\title{
An integrated precise engineering for micro forming
}

\author{
Ming $\mathrm{YANG}^{1, *}$, Tetsuhide Shimizu ${ }^{1}$, Jun $\mathrm{Hu}^{1}$, and Tomomi Shiratori ${ }^{2}$ \\ ${ }^{1}$ Tokyo Metropolitan University, Faculty of system design, 191-0065 Tokyo, Japan \\ ${ }^{2}$ Komatsuseiki kosakujo Co., , Japan
}

\begin{abstract}
An integrated precise engineering was proposed and developed to push the micro metal forming technology to higher level for manufacturing micro metallic devices in this study. A textured Diamond Liked Carbon (DLC) coating was applied to micro die for improving tribological performance. Highenergy assisted processes, such as die-embedded localize heating and ultrasonic vibration systems were developed to improve formability of micro materials and accuracy of processes. The results show that the integrated precise engineering solved the issues due to the size effects, and improved very much the tribological properties, formability of work materials and accuracy of product. Furthermore, the integrated precise engineering was applied in micro forming to manufacturing a micro metallic pump which realized commercialization.
\end{abstract}

Keywords: Micro forming, Textured DLC coating, High-energy assisted process, fine grain material, micro metallic pump

\section{Introduction}

Metal forming in sub-millimeter or micrometer scales becomes a key technology for the audio-video or information technological devices due to miniaturization of structure parts. Furthermore, fabrication of micro devices, such as Bio-MEMS (Micro Electrical mechanical Systems) or micro equipment for medical application based on metal forming has been attended attractive as well due to metals have the properties of ductility, conductivity and bio-compatibility [1,2]. However, many issues, such as accuracy of machinery, scattering in properties of thin materials, fabrication of tools/dies, assembly of micro components, still exit in metal forming in micro and meso scales. Researches on formability, flow resistance of thin foil materials in micro and meso scales were performed previously. Not only the flow stress, but also accuracy of the products is influenced by size effects $[3,4]$. Springback properties of thin foils in various thickness and grain sizes change due to its size effect [5-8]. As the size is scaling down, the accuracy of production and forming limit of workpiece usually become worse because of occurrence of the size effects [9]. In general, the dimensional accuracy needs to be increased according to down-sizing of product. It is important to develop the micro forming processed with an integrated precise engineering to improve formability of the work material and accuracy of product. [10].

The authors have been working on a novel micro metal forming system in which micro parts or units are fabricated by micro press forming and automatic assembly processes in a progressive die, and developed several processes, such as a high-energy assisted micro forming, which combines heating and vibration to improve formability of the material and accuracy of products by using servo-press system with a resistance heating system and vibration system embedded in the dies. Furthermore, a textured Diamond Liked Carbon (DLC) coating system was applied to micro forming die in order to improve tribological properties in the processes. Micro deep drawing and micro forging was carried out to evaluate the performance of the highenergy assistance and effect on formability of the material and accuracy of the products.

In this study, progresses in development of the die surface treatment, high-energy assistant forming process, and application of the integrated precise engineering to manufacturing the metallic devices are introduced.

\section{Integrated precise engineering for micro forming}

Most significant issues in micro forming due to the size effects should be overcome to achieve the targets. In this chapter, the authors will introduce some approaches to overcome the issues due to the size effects: development of the die surface treatment using textured DLC coating to improve tribological properties and its evaluation by a bending test; development of a localize contact heating system with die coating by controlling

\footnotetext{
Corresponding author: yang@tmu.ac.jp
} 
electrical resistance of the film coated, and an die embedded ultrasonic vibration system for the highenergy assistant forming processes in order to improve formability of the work materials and accuracy of products; and application of the integrated precise engineering to manufacturing a micro metallic pump.

\subsection{Micro-texturing of DLC thin film coatings for surface treatment of micro dies}

Due to the low effect of lubricant in microscale dimensions, the tribological issues in micro forming confronts with further severe problems to enhance the performance of micro forming dies [11]. In particular, tool life of the micro-dies has not been well satisfied the industrial requirement. Against these backgrounds, a number of applications of hard film coatings on micro forming die substrates have been gradually increasing. Particularly, diamond like carbon (DLC) films has been received a great attention for its excellent tribological performance, such as low friction coefficient and high wear resistance under dry friction [12].

The authors have been focusing on the tribological performance of micro-textured DLC films under dry sliding friction. In view of the application to the microforming dies, tribological properties were investigated under the contact state as operated in microforming process. Firstly, the micro-textured DLC films were fabricated by masking with metallic mesh during the ionized physical vapor deposition (I-PVD). Then, the tribological properties of this micro-textured DLC films were evaluated by ball-on-disk type friction tests. Based on this evaluation, the effect of the texture size on the dry friction and wear performance were discussed. It has been experimentally proven that surface texturing works to improve the friction characteristics by promoting discharge of abrasion powder at the contact interface $[13,14]$.

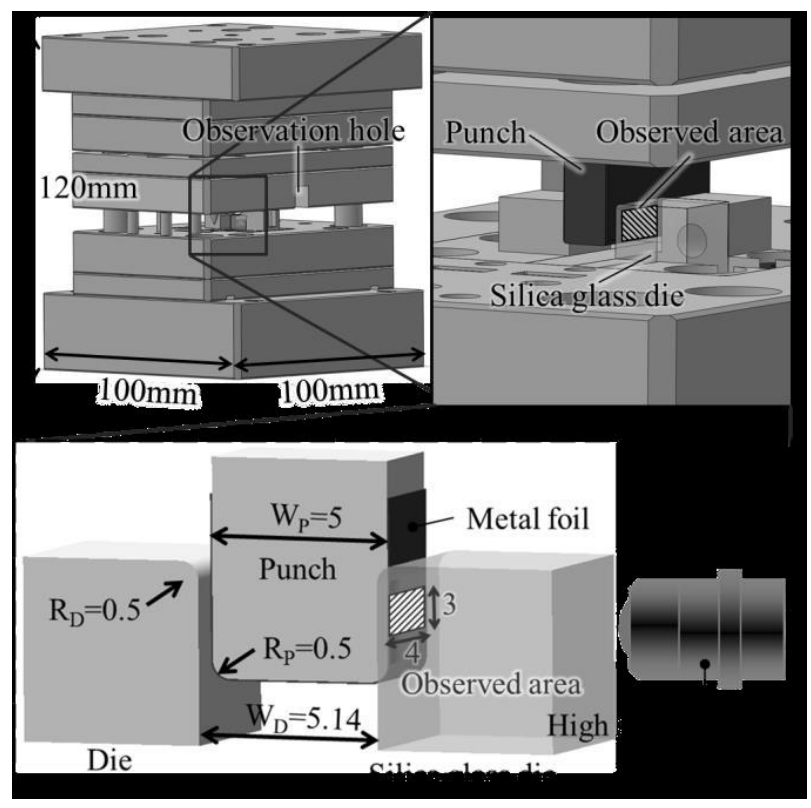

Fig.1. Schematic of in-situ observation of micro bending test
To verify the tribological effect in micro forming processes, a micro bending test with in-situ observation system was performed by using the textured DLC coating on the die surface. Fig. 1 shows the outline of the bending die and the method for observing the sliding surface in situ during processing. The bending die is a compact die with each side about $100 \mathrm{~mm}$, and the die dimensions are: die shoulder radius $R_{D}$ punch shoulder radius $R_{P}=0.5 \mathrm{~mm}$, punch width $\mathrm{Wp}=5 \mathrm{~mm}$, die width $\mathrm{W}_{\mathrm{D}}=5.14 \mathrm{~mm}$. By making one of the bending die $(8 \mathrm{~mm} \times 8 \mathrm{~mm} \times 8 \mathrm{~mm})$ with quartz glass, it was possible to observe the sliding interface where the workpiece and die contact with each other by descent of the punch from the back of the die through the glass die. We developed a system capable of recording and observing the observable area of the glass die shoulder end portion, $4 \mathrm{~mm} \times 3 \mathrm{~mm}$, at the maximum magnification of 750 times by a high speed camera with a zoom lens. The prepared metal mask was fixed along the shape of the quartz glass die surface, and DLC film was coated on the micro die to surface texturing. Same conditions are utilized for the coating process as same as the previous study [13]. Fig. 2 shows the optical image of the fabricated texture shape and the AFM image on the die shoulder. Texture width of about $45 \mu \mathrm{m}$, texture interval of about $20 \mu \mathrm{m}$, texture height of about $1.1 \mu \mathrm{m}$, and even a glass die shoulder portion with a shoulder radius of $500 \mu \mathrm{m}$ succeeded in creating the surface having a uniform texture structure.

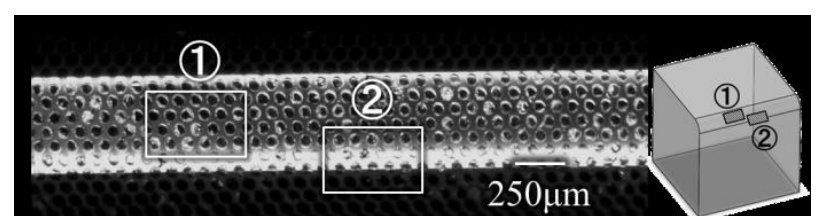

(a) Optical image of die shoulder

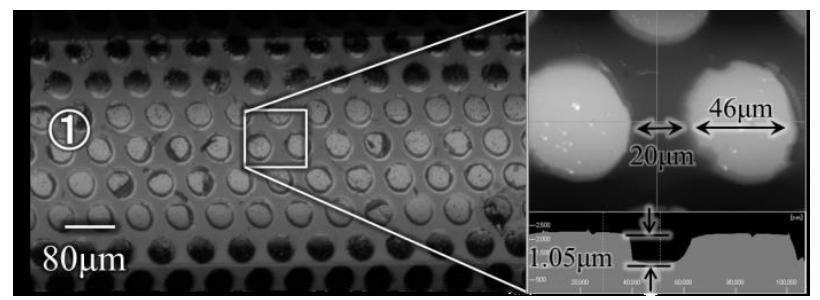

(b) Optical image

(c)AFM image

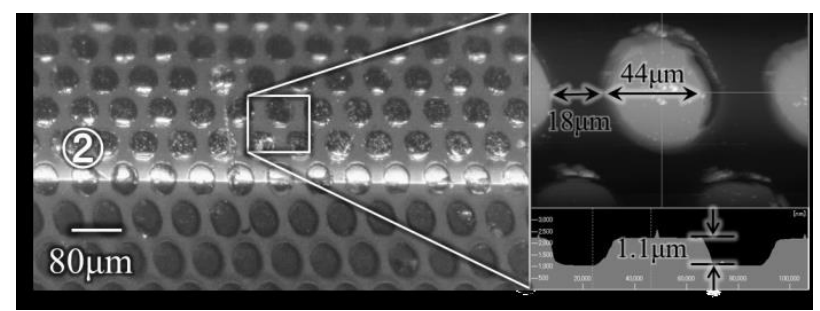

(d) Optical image

(e)AFM image

Fig.2. Optical and AFM images of textured DLC on micro die

In order to verify the practicality of this device, DLC was formed on the quartz glass die surface and in-situ observation of the peeling process of the DLC film during micro bending was performed. A stainless steel foil material (JIS: SUS $304 \mathrm{H}$ ) having a thickness of 
$50 \mu \mathrm{m}$ was used as a test material and processed at a punch descending speed of $1 \mathrm{~mm} / \mathrm{s}$ under no lubrication. In-situ observation images of the sliding interface between the micro die and the workpiece at the 5th, 10th, and 20th processing times in the micro press bending test are shown in Fig 3. The DLC coating without texture, called was the flat DLC (FDLC), also applied for the comparison. In this case, the DLC film at the end of the die shoulder was peeled off by the fifth time of forming, and scratch-like damage occurred in a part of the DLC film by the tenth. Furthermore, the DLC film was peeled off in the whole area of the observation range by the 20 th, so the test was stopped. On the other hand, in the die in which the textured DLC (TDLC) was coated, although partial peeling of the DLC film was observed at the end of the die shoulder, remarkable peeling as in the case of the die with the FDLC coated could be confirmed even at the 20th processing was completed without damages even after processing 100 times. The effect of the texture size on the dry friction and wear performance is confirmed in the micro forming.

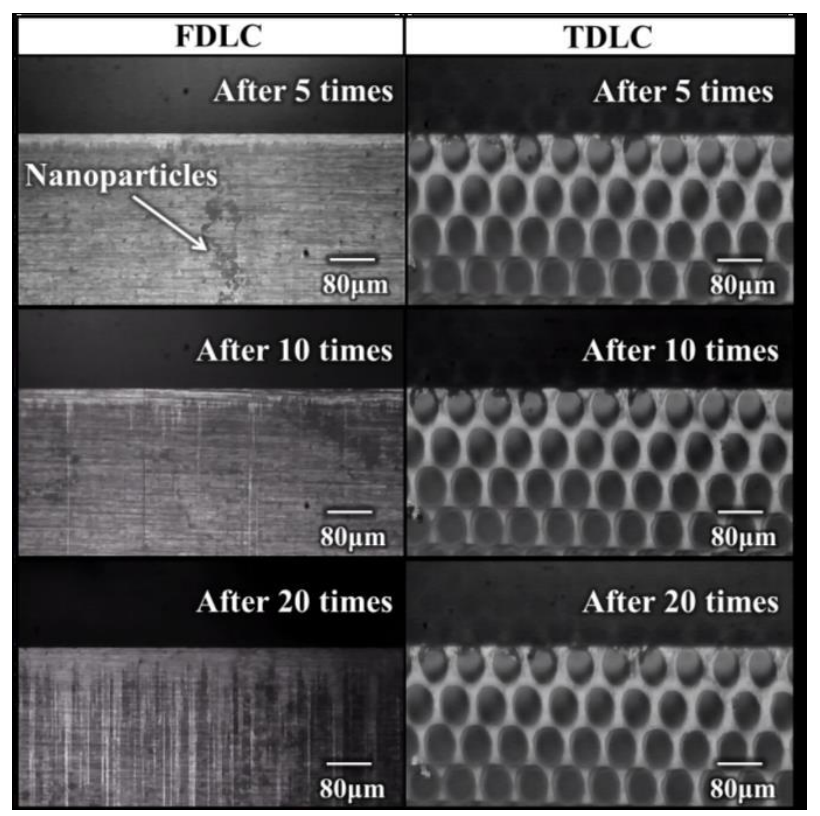

Fig. 3. In-situ observation images during progressive micro bending test

\subsection{Developing high-energy assisted forming processes}

Improvement of forming limit of the work material and accuracy of product is required for micro forming processes as discussed previously. It is known that heating work material during the process can improve ductility of workpiece and make the deformation more uniform in micro scale [15]. The authors developed a die embedded system for localized heating or other highenergy assistance during the process to achieve micro forming with higher forming limit and accuracy [16]. In next sections, author will introduce development of two high-energy assisted forming processes: a localized heating system by using a die with an electrical resistance controlled surface coating, and an ultrasonic vibration assistance with die-embedded vibrator.

\subsubsection{Localized Heating system}

The desktop servo-press system with a resistance heating system embedded dies was developed by the authors [17]. The heat-assisted micro forming system with resistance heating was designed to satisfy low energy consumption and high forming accuracy by heating only the workpiece material and limiting the heat transferring to tools. Two contact probes embedded in the dies to keep contact of probes to workpiece and keep heating during the forming process. Because of down-sizing in dimensions of workpiece the targeted temperatures of several hundred Celsius degrees could be achieved in a few seconds and the consumed energies were limited to a small amount, and deformation of the workpiece becomes more ductile and uniform in the heat-assisted micro deep drawing process. However, several issues in temperature distribution and conductivity properties of workpiece need to be solved for application in real manufacturing processes. Here, temperature distribution is dependent on the positioning of the electrode and shape of workpieces. The variety of the electrical resistivity in the working materials also influences the process conditions [18].

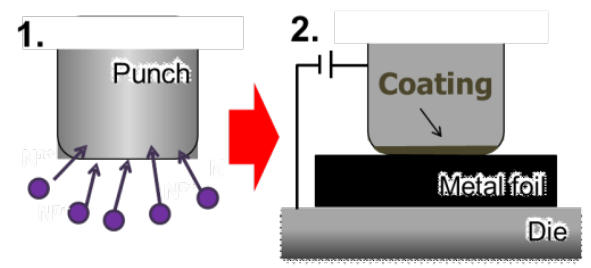

3.

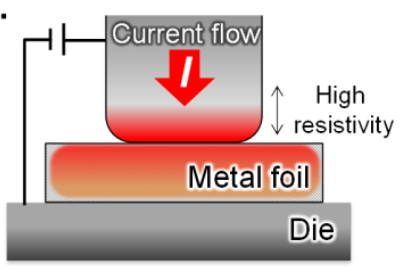

Fig. 4. Conception of Surface modification for heating

In order to increase the versatility of the heating system, a novel heating system is developed by using die surface as the heat source. The authors select proper coating system for performing both of mechanical function for improving tribological properties and electrical functions for heating workpiece locally. The die with the particular coating, which has higher electrical resistivity, was applied as the die embedded heating system. Fig. 4 shows the conception of the heating system. Since the surface layer of the die has higher electrical resistivity and becomes a heating source during the current flowing from upper die through specimen to lower die, this method can achieve the heating of work materials independent from its resistivity and its geometry. In this study, the surface coating with $\mathrm{AlCrSiN}$ films of thickness $0.5,1.0 \mu \mathrm{m}$ were deposited on upper die and bottom die for compression tests and micro forging tests. Pure titanium, pure copper, and stainless steel 
(JIS:SUS304 with ultra-fine grain size) rods $\phi 1 \mathrm{~mm} \times 2$ $\mathrm{mm}$ were prepared for compression tests and SUS304 UFGSS of thickness $0.2 \mathrm{~mm}$ was prepared for forging tests. Diameter of upper die for compression test is 10 $\mathrm{mm}$ and that for forging test is $1 \mathrm{~mm}$. The range of flew current density which was defined as the current intensity divided by the initial cross-sectional area was $0-64 \mathrm{~A} / \mathrm{mm}^{2}$.

Fig. 5 shows resultant temperature rising for various current densities during the compression test. As results, higher temperature of work materials was obtained for the die coated $\mathrm{AlCrSiN}$ films than that without surface treatment. In particular for the Ti rod under $64 \mathrm{~A} / \mathrm{mm}^{2}$, there was a temperature difference of $400{ }^{\circ} \mathrm{C}$ between the die with and without surface treatment. Forming load also decreased by increasing the temperature of work materials by using the surface treated dies. As for the forging tests, depth of forged parts increased by the proposed method. Furthermore, micro forging test also shows that a precise contour shape can obtain by using this heating system, which is very difficult by using standard forging in room temperature because of its high strength and low ductility due to the ultra-fine grain structure.

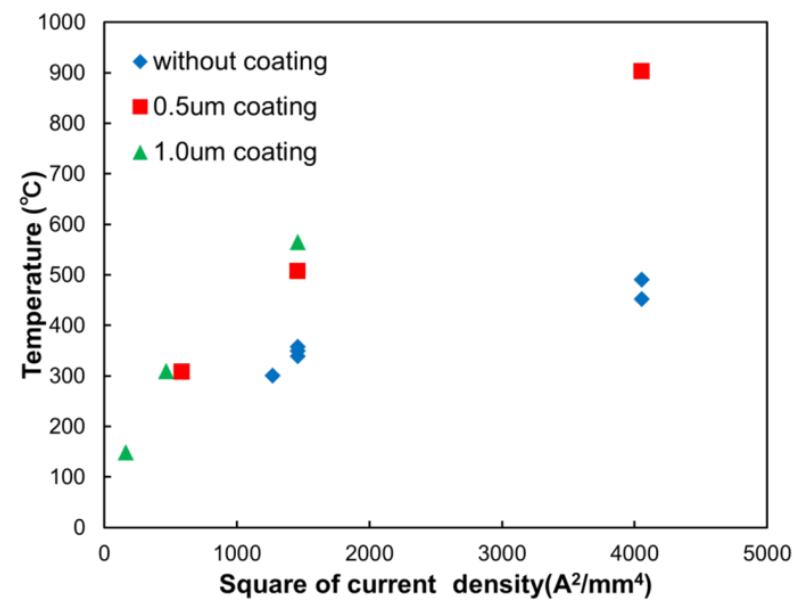

Fig. 5. Comparison of temperature rising with and without surface coating

\subsubsection{Vibration assisted micro forming}

Another high-energy assisted forming is of using high frequency vibration. Since the amplitude of the vibration becomes relatively larger as dimension of the material decreases, and the effect also increases relatively in the case of micro forming as compared with macro forming. Fig. 6 shows topography image of the Phosphor bronze C5191 foil surface before and after vibration assisted micro forming process. Surface roughness Ra was reduced from $102 \mathrm{~nm}$ to $21 \mathrm{~nm}$. In this case, static punch load was $305.7 \mathrm{MPa}$ and vibration frequency and amplitude were $1 \mathrm{kHz}$ and $4.7 \mu \mathrm{m}$, respectively. It is found the surface asperities are deformed to very smooth with almost no asperity remained, and as a result, the surface roughness became much lower. What should be noticed is that the nominal static stress applied on the surface was far smaller than the yield stress of Phosphor bronze C5191. This

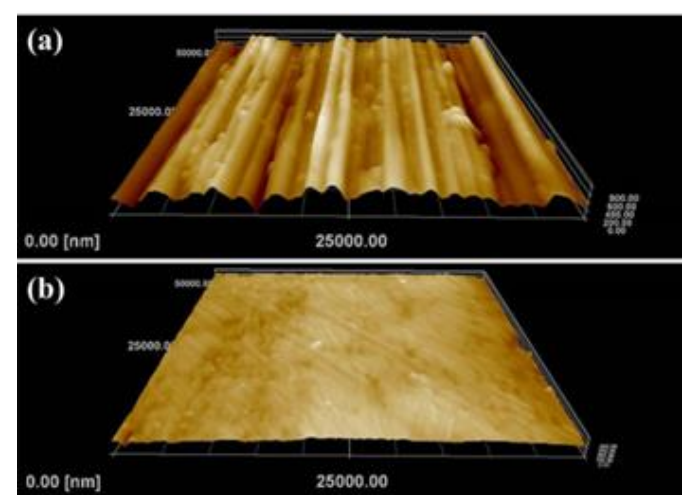

Fig. 6. Topography of the Phosphor bronze C5191 foil surface (a) before $(\mathrm{Ra}=102 \mathrm{~nm})$ and (b) after vibration assisted forming process with frequency of $1 \mathrm{kHz}(\mathrm{Ra}=21 \mathrm{~nm})$

indicates that the presence of vibration induced plastic deformation of the surface layer significantly [19].

Different frequency and vibration amplitude give different strain on the thickness direction with different energy density. As a result, the deformation of asperity and surface finishing results are different. Fig. 7 shows the surface reduction obtained at different amplitudes and frequency and without vibration. It is found that

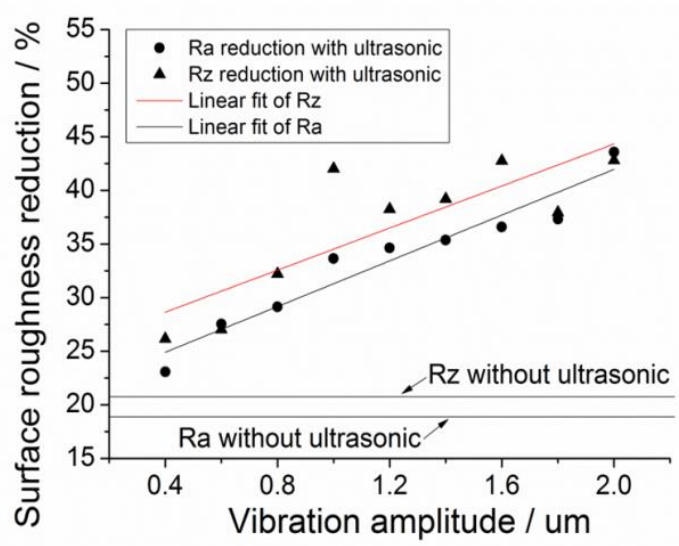

(a)

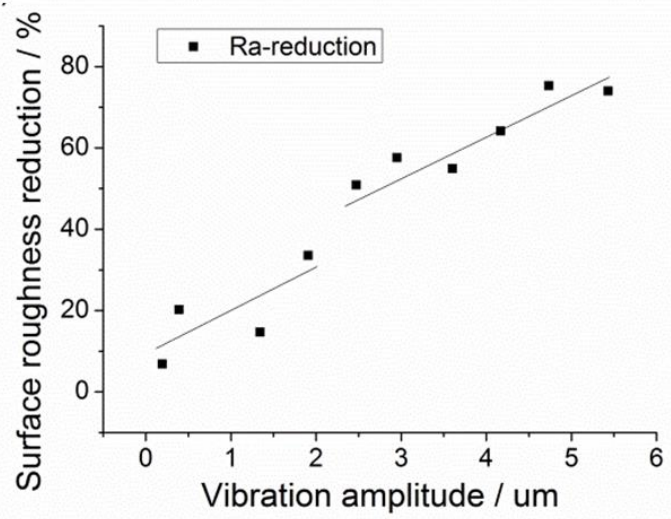

(b)

Fig. 7. Relation between surface roughness reduction and vibration amplitude for (a) vibration frequency $100 \mathrm{kHz}$ and (b) vibration frequency $1 \mathrm{kHz}$ 
reduction of the roughness increases with increase of the amplitude for both frequencies. Three different effects work during the vibration assisted forming process: (1.) friction reduction between the tools and workpiece due to varied contact, (2.) impact force while the departed punch retouches the workpiece with high acceleration, (3.) material softening due to high frequent elastic waving. In this case, vibration with high frequency accompanied material softening effect and as a result, the reduction ratio was higher than that with the low frequency for similar amplitude by comparing Fig. 7(a) and (b) for amplitude smaller than $2.0 \mu \mathrm{m}$. Furthermore, the reduction ratio jumped up higher for the amplitude larger than $2.5 \mu \mathrm{m}$ (Fig. 7(b)). It is because that while the amplitude became larger than $2.5 \mu \mathrm{m}$, the punch departs from contact and retouches the workpiece within one vibration cycle, and as a result, an impact force added on the surface of workpiece [20].
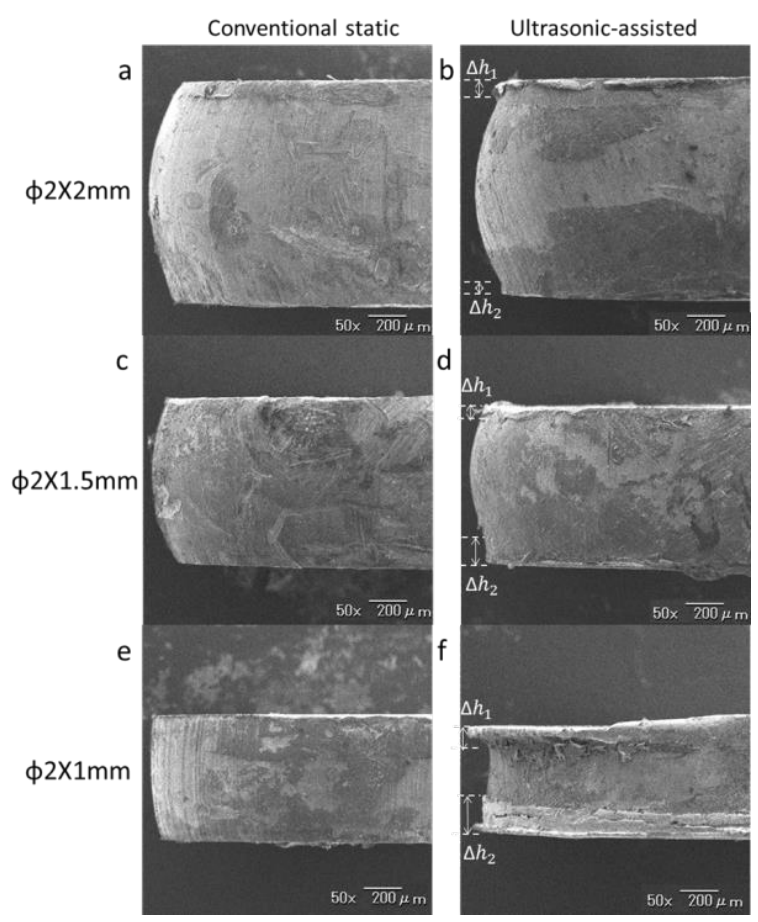

Fig. 8. SEM images of typical specimens in different original height after conventional static and ultrasonic-assisted compression

A vibrator with natural frequency of $60 \mathrm{kHz}$, was designed for micro forming Punch is connected on the vibrator and the vibration is further amplified by the punch with staircase structure, and maximum amplitude of $3.2 \mu \mathrm{m}$ can be achieved on the top surface of the punch. A compression test is performed by the vibration system. The SEM images of typical deformed specimens in different original height after conventional static and ultrasonic-assisted compression were shown in Fig. 8. In the conventional static compressions without ultrasonic vibration in Fig. 8(a), (c) and (e), all 3 specimens had a significant barrelling shape, which indicated a relative high friction value at the top and bottom interface. However, when the compressions were conducted with ultrasonic assistance, both top and bottom surfaces had more expansion and even antibarrelling shapes in depth of $\Delta \mathrm{h} \_1$ and $\Delta \mathrm{h} \_2$ were formed around the corners in every specimen, as shown in Fig. 8(b), (d) and (f). It can be seen that the deformation of surface layer becomes more significant for the workpieces with smaller height. This phenomenon involves dynamic impact effect, which is caused while the punch detaches the workpiece in the case of the amplitude larger than springback of workpiece [21].

\subsection{Manufacturing of micro metallic device with fine grained material}

For manufacturing micro metallic devices, the authors integrated the precise engineering technologies including the material development and the die fabrication. A micro pump was developed by using precise piercing and diffusion bonding processes with ultra-fine grain stainless steel foil (SUS304) [22]. Fig. 9 shows the Electron Back Scatter Diffraction (EBSD) results of thickness $10 \mu \mathrm{m}$ foil. This grain phase almost changed from general austenitic phase to strain-inducedmartensitic phase. This could be regarded as "fullmartensitic stainless steel". This material can achieve diffusion bonding at a low temperature of $973 \mathrm{~K}$ [23].

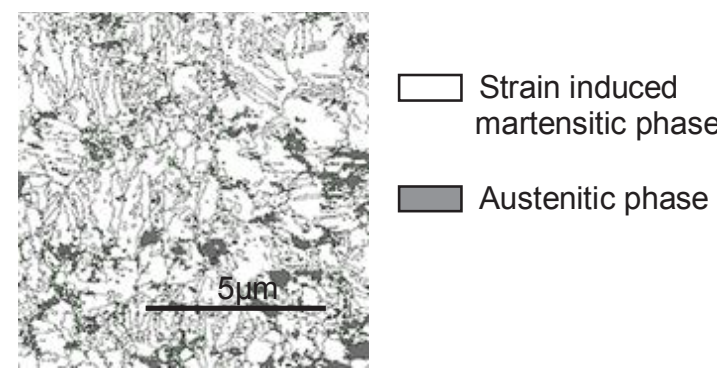

Fig. 9. Grain condition of fine-grained SUS304 observed by SEM with EBSD

Furthermore, the average grain size decreased to $1.5 \mu \mathrm{m}$, which brings in improvement of the deformation uniformity and the production quality in the metal forming processes. Moreover, in order to achieve a diffusion bonding under the low stress, surface

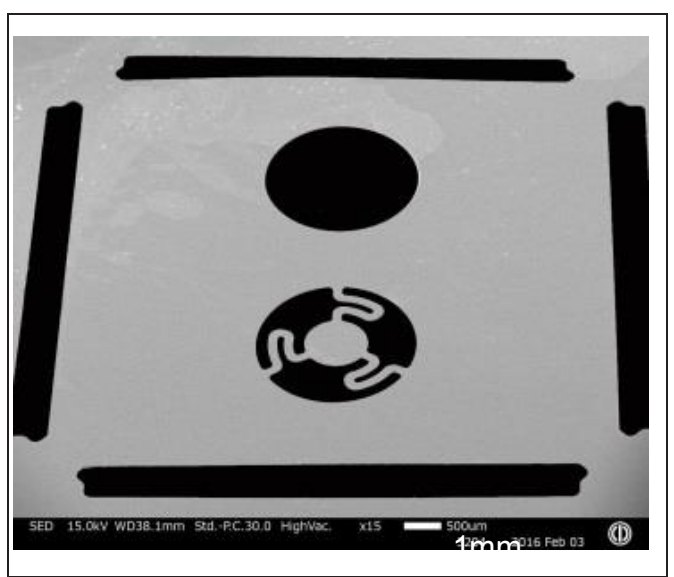

Fig. 10. SEM image of pierced $0.010 \mathrm{~mm}$ foil 


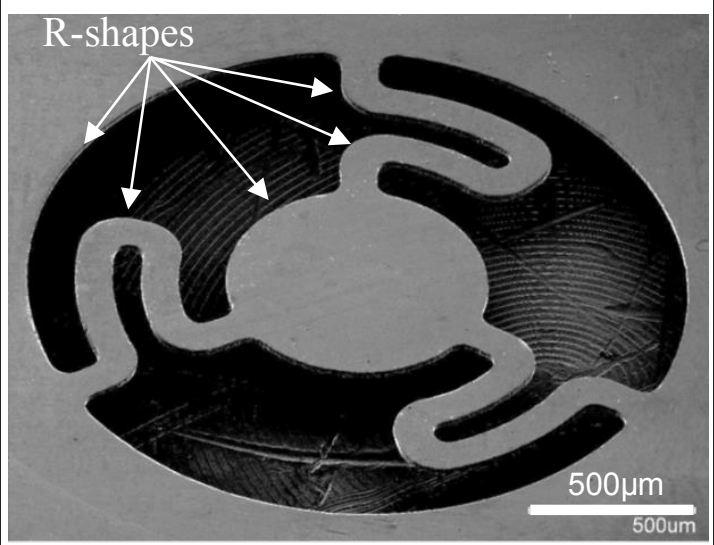

a) Rollover side of U-shapes

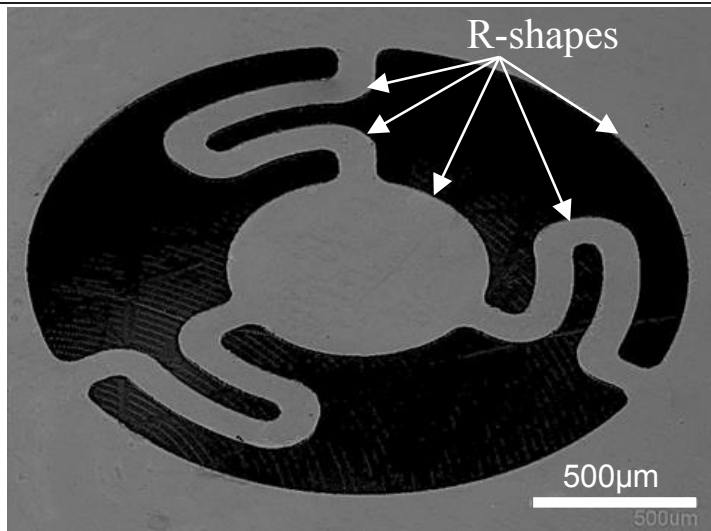

b) Fractured surface side of U-shapes

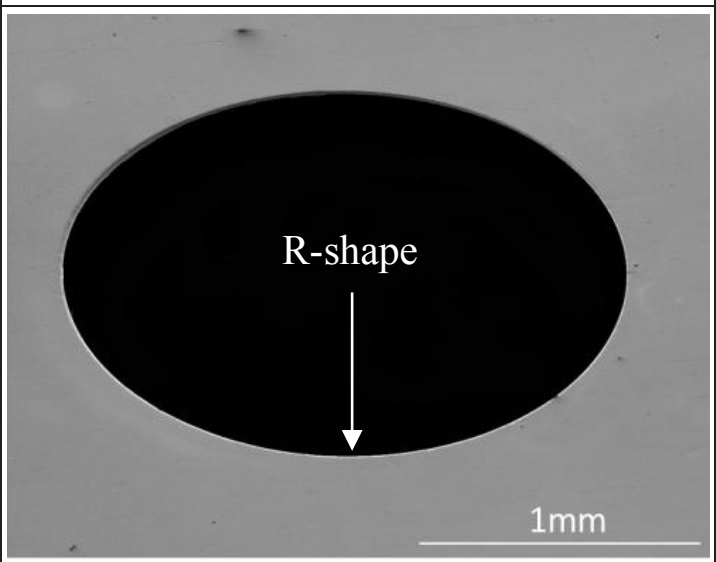

c) $\varphi 2 \mathrm{~mm}$

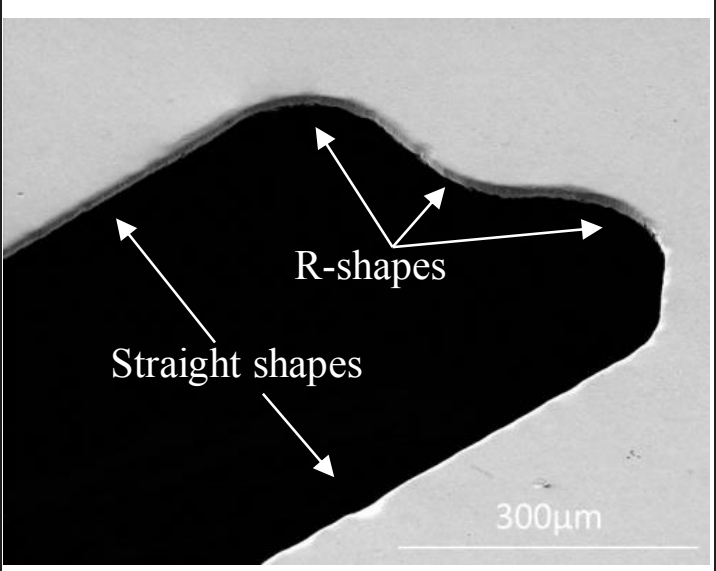

d) Irregular shape hole

Fig. 11. SEM image of enlarged pierced holes roughness was also improved. The punch for the piercing process was cut by penetrating it into the die to fabricate zero clearance between the punch and the die in order to guaranttee the dimension accuracy and the edge shape. Fig. 10 shows the SEM image of pierced $0.010 \mathrm{~mm}$ stainless SUS304 foil. Fig. 11 shows details of pierced shapes and enlarged images. The shapes of pierced holes and irregular shapes are uniform in sheared surface and there are almost no burrs. Finally eight components of the micro pump were joined by diffusion bonding at $973 \mathrm{~K}$. Fig. 12 shows the photo image of the pump and its components. The pump is driven by the piezo actuator, and the diaphragm is deformed accordingly. The flow rate is regulated by two valves allocated inlet and outlet of the pump, which linked to the vertical movement of the diaphragm. Dimensional accuracy of the valves determine the pump performance since it affects leakage property of pump significantly. Performance of the pump shows that the pierced metal foil maintains its flatness enough to stabilize the performance of metal micro-pump, such as flow rate stability and repeatability [24].

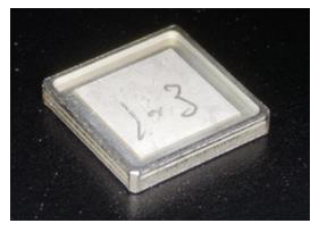

Photo image

PZT
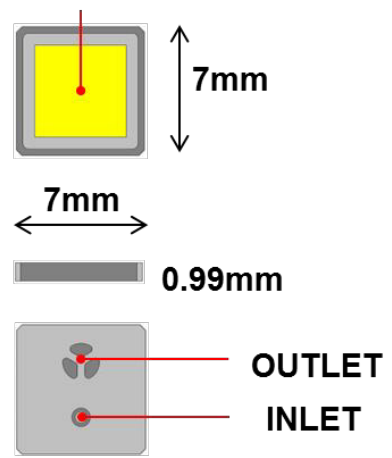

PZT

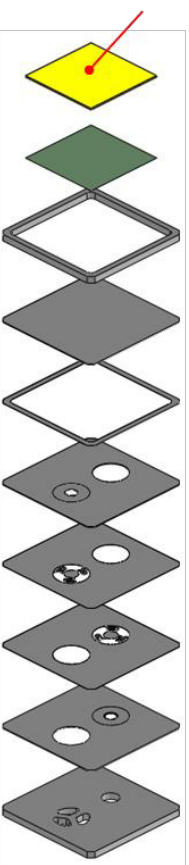

Fig. 12. Confuguration of the metallic pump and its components

\section{Conclusions}

An integrated precise engineering is proposed and developed for micro forming in this study. The integrated approach can not only improve formability of the work material, but also accuracy of product. The main findings are summarized below.

- The die surface was treated using textured DLC and its effect was evaluated by a micro bending test. The tribological properties were improved by stabilizing friction during the sliding between the workpiece and die and reducing wear rate of the die. 
- A localize contact heating system with die coating by controlling electrical resistance of the film effectively reduced flow stress and improved ductility of the work material during micro forming processes.

- A die embedded ultrasonic vibration system improves formability of the work materials and especially enhance deformation in the surface layer.

- The integrated precise engineering was applied to manufacture a micro metallic pump which realized commercialization.

\section{References}

1. Geigerl M, Kleine M, Eckstein R, Tieslerl N, Engel U. Microforming. CIRP Ann 2001; 50(2): 445-462.

2. Engel U, Eckstein R. Microforming-from basic research to its realization. J Mater Process Tech (2002); 125-126: 35-44.

3. Kals TA, Eckstein R. Miniaturization in sheet metal working. J Mater Process Tech, 103: (2000), 95-101.

4. Suzuki K, Matsuki Y, Masaki K, Sato M, Kuroda M. Tensile and microbend tests of pure aluminum foils with different thicknesses. Mater Sci Eng A (2009), 513-514: 77-82.

5. Diehl A, Engel U, Merklein M. Size effects in bending processes applied to metal foils. Prod Eng Res Devel, (2010); 4: 47-56.

6. Li HZ, Dong XH, Shen Y, Diehl A, Hagenah H, Engel U, Merklein M. Size effect on springback behavior due to plastic strain gradient hardening in microbending process of pure aluminum foils. Mater Sci Eng A (2010); 527: 4497-4504.

7. Li HZ, Dong XH, Wang Q, Shen Y, Diehlc A, Hagenah H, Engel U, Merklein M. Determination of material intrinsic length and strain gradient hardening in microbending process. Int $\mathrm{J}$ Solids Struct (2011); 48: 163-174.

8. Aoyama T, Shimizu T, Zheng Q, Yang M. Effect of Heating on Springback in Heat Assisted Microbending. Adv Mater Res (2014); 939: 409-414.

9. Vollertsen F, Biermann D, Hansen HN, et al. Size effect in manufacturing of metallic components. CIRP Ann 2009; 58: 566-87.

10. M. YANG, "Fabrication of MEMS Using Micro Metal Forming Process", Proc. ICNFT, (2004), pp.135-140.

11. Engel, U., Tribology in Microforming. Wear, 260(2006), 265-273.

12. Grill, A., 1997. Tribology of diamond like carbon and related materials: an updated review. Surface and Coating Technology, 94-95(1997), 507-513.

13. Tetsuhide Shimizu, Tai Kakegawa, Ming Yang, Micro-texturing of DLC thin film coatings and its tribological performance under dry sliding friction for microforming operation, Procedia Engineering 81(2014), pp.1884- 1889.
14. T. Kakegawa, T. Shimizu, Y. Sagisawa, M. Yang, Surface Texturing on Micro-Die and In-situ Observation of Its Dry Friction and Wear Behavior, J. of JSTP, 56-657(2016), 891-896.

15. B. Eichenhueller,E. Egerer,U. Engel, Microforming at elevated temperature-forming and material behavior, The International Journal of Advanced Manufacturing Technology,33(2007), 119-124.

16. M. Yang, T. Shimizu, Novel processes and related technologies for micro metal forming, Int. J. Materials and Product Technology, Vol. 54, Nos. 1/2/3 (2017), 32-44.

17. H. Tanabe, M. YANG, Design and Evaluation of Heat Assisted Microforming System, Steel Research International, Special Edition (2011), 1020-1024.

18. Qiu Zheng, Tetsuhide Shimizu, Ming Yang, Numerical Analysis of Temperature Distribution and Its Optimization for Thin Foils in Micro Deep Drawing Assisted by Resistance Heating, Steel Research International, 85 (2015), 1-8.

19. Yang Bai, Kenji Nishikawa, Ming Yang, Metal Surface Modification with Vibration-Aided MicroForging, Materials Transactions, Vol. 53, No. 3 (2012) pp. 489-494.

20. Yang Bai, Ming Yang, Investigation on mechanism of metal foil surface finishing with vibrationassisted micro-forging, J. of Materials Processing Technology 213 (2013), pp.330-336.

21. Hu, J., Shimizu, T., Yang, M., "Impact effect of superimposed ultrasonic vibration on material characteristics in compression tests." Procedia Engineering, (2017).

22. T Shiratori, Y. Suzuki, S. Nakano, M. Yang, and T. Komatsu, Effects of grain size on the sheared surface in micropiercing of austenitic stainless steel SUS304, Manufacturing Rev., 2-9(2015), 1-6.

23. M. Katoh et al., "Reduction of diffusion bonding temperature with recrystallization at austenitic stainless steel," Tetsu-to-hagane, 102 (2016), 34-39.

24. T. Shiratori, S. Nakano, M. Katoh, Y. Suzuki, T. Aihara, M. Yang, Development of metal MEMS manufacturing technologies using pierced metal foil and diffusion bonding process at low temperature, Proc. 4M/IWMF, (2016). 